\title{
Attenuation of overshadowing as a function of nondifferential compound conditioning trials
}

\author{
W. P. BELLINGHAM and KATY GILLETTE \\ Australian National University, Canberra 2600, Australia
}

\begin{abstract}
Using a classical conditioning procedure, four groups of eight rats each were given 50 to 4,050 conditioning trials with a simultaneous tonelight compound stimulus paired with noncontingent delivery of a water dipper. The anticipatory response of entering the magazine during the CS served as the conditioned response. Following training, each group was tested in extinction such that one-third of the test trials were to the tone-light compound, one-third to the tone alone, and one-third to the light alone. Rats that had received 50 or 250 conditioning trials showed very little resistance to extinction to the light alone, whereas resistance to the tone was substantial and similar to that for the tone-light compound. After 1,250 and 4,050 conditioning trials, responding to the light increased to match the high levels of responding elicited by the tone and tone-light compound. The results present difficulties for both "continuity" and "noncontinuity" theories of stimulus selection.
\end{abstract}

It has been established that overshadowing can result from a single stimulus exposure (James \& Wagner, 1980; Mackintosh, 1971) as well as from multiple exposures. James and Wagner (1980) have recently delineated the implications of one-trial overshadowing for various approaches to overshadowing and stimulus selection in general. They concluded that some form of distributed attention model (e.g., Sutherland \& Mackintosh, 1971) or stimulus interaction model (e.g., Hull, 1943) might provide reasonable explanations of single-trial effects. James and Wagner argued that interpretation of overshadowing as a special case of "blocking" (i.e., Mackintosh, 1975; Rescorla \& Wagner, 1972) are not viable, in that overshadowing would require multiple trials.

The experiment described below is part of a larger ongoing study but is being reported because it pertains specifically to the dynamics of overshadowing. It has been shown that when a compound stimulus, composed of equisalient component stimuli, is nondifferentially reinforced, the components systematically lose strength as a function of the number of training trials; that is, configural conditioning is demonstrated (Bellingham $\&$ Gillette, in press). The concern of the present study was to observe changes in associative strength of component stimuli, as a function of training trials, when they were unequal in their saliency. There would seem to be several possible outcomes of this manipulation. First, the initial overshadowing of the weaker component would be sustained regardless of the number of

The authors would like to thank Geoffrey Jones for technical assistance and for assistance in data collection. The research was supported by an Australian Research Grants Committee Award (A28015954) to both authors. Requests for reprints can be directed to either author at the Psychology Department, Australian National University, P.O. Box 4, Canberra, A.C.T. 2600, Australia. training trials. Second, the degree of overshadowing would increase progressively. Third, the strong component would weaken and a configure would develop. Last, the weaker stimulus would gain strength with continued training. Given current formulations of associative learning, the last alternative would seem the least likely. However, Thomas, Berman, Serednesky, and Lyons (1968) found that an "overshadowed" component of a sequential compound gained strength after continued training, giving some reason to believe that the alternative is plausible.

\section{METHOD}

Subjects

Thirty-two male Wistar hooded rats were obtained from the Psychology Department's breeding colony at the Australian National University. The rats were 90-100 days old when isolated in individual wire cages in which food was provided ad lib. The animals were adapted to a $23.5-\mathrm{h}$ water-restriction schedule for 10 days prior to the beginning of the experiment. Throughout adaptation and conditioning, the animals were subjected to a $12 / 12$ light/dark cycle, with lights on from $0600 \mathrm{~h}$.

\section{Apparatus}

Training and testing were conducted in four custom-designed operant chambers. Each chamber was enclosed in a wooden sound-attenuating enclosure that was ventilated by a blower that provided a 75-dB masking noise. All sound levels reported are re $20 \mathrm{microN} / \mathrm{m}^{2}$.

The operant chambers were $30.5 \times 20.0 \times 19.5 \mathrm{~cm}$ and were fitted with a water dipper activated by a rotary solenoid. The capacity of the cup mounted on the dipper arm was $.1 \mathrm{ml}$. The cup entered through the center of the floor of a magazine recess $(6.5 \times 6.5 \times 7.0 \mathrm{~cm})$ situated on the front wall. The floor of the chamber consisted of stainless steel bars, $1.0 \mathrm{~cm}$ in diameter and $1.3 \mathrm{~cm}$ apart, placed parallel to the front wall.

The stimuli were provided by a light and a miniature speaker located within the magazine recess. The stimulus light was a 24-V 5-W bulb mounted above a brushed plastic lens centered over the dipper cup and flush with the ceiling of the recess. During training and testing, the light (L) was pulsed at the 
rate of 5 times/sec. In a constant "on" condition, it provided $550 \pm 10 \mathrm{~lx}$, as measured from the center of, and flush with the face of, the magazine entrance. Two $24-\mathrm{V} 25-\mathrm{mA}$ houselights provided a low level of intertrial illumination (approximately $1.25 \mathrm{~lx}$ ). A miniature speaker was mounted in the center of the back wall of the magazine recess such that it faced the entrance to the magazine. The speaker provided a $105 \pm 2 \mathrm{~dB} 1,000-\mathrm{Hz}$ tone (T) (measured from the same position as the light), which was pulsed 5 times/sec in phase with the light. The tone was generated by a BWD 141 sine- and square-wave generator coupled to a Rapar PA (TPA-30) amplifier. All programming, stimulus delivery, and response measures were controlled by Digital $\mathrm{K}$-logic solid state circuitry and a punched-tape reader.

Response measures (i.e., number of magazine entrances) were obtained by installing photocells on the side walls of the magazine recess $2.0 \mathrm{~cm}$ from the entrance itself and $.2 \mathrm{~cm}$ above the floor of the recess. In order to prevent the animals from lying with their snouts in the magazine recess, and thus breaking the photobeam continuously, a $1.5-\mathrm{cm}$-high stainless steel plate was positioned across the base of the magazine entrance.

\section{Procedure}

Design. The design used was a basic factorial with four levels for the between-subjects variable (level of training) and three levels for the within-subjects variable (test stimulus). Eight animals were randomly assigned to each of four levels of training.

Conditioning. The procedure involved "classically" conditioning a magazine entrance to the $\mathrm{T}+\mathrm{L}$ compound for 50 , $250,1,250$, or 4,050 trials at 50 trials/day. On each trial $\mathrm{T}+\mathrm{L}$ was presented for $8 \mathrm{sec}$. The dipper was presented noncontingently during the last $3 \mathrm{sec}$ and was withdrawn simultaneously with the $\mathrm{T}+\mathrm{L}$ offset. The CS was presented on a VI 60-sec schedule with a range from 30 to $90 \mathrm{sec}$. A magazine entry, breaking the photobeam, constituted a response that was recorded separately for the initial $5 \mathrm{sec}$ of the CS period and the 3-sec UCS period. Multiple responses, during either period, were counted as a single response.

At the commencement of each conditioning session, the rats were deprived of water for $22.5 \mathrm{~h}$. Immediately after each conditioning session, water was available for $30 \mathrm{~min}$ in the home cage.

Testing. Testing was always conducted on the day following the last conditioning session. For each level of conditioning, extinction consisted of 51 nonreinforced trials on which $\mathrm{T}+\mathrm{L}$, $\mathrm{T}$, and $\mathrm{L}$ were presented 17 times each. Responses were recorded separately for the CS and UCS periods, as during the conditioning phase. Due to programming constraints, the order of stimulus presentations could not be randomized and followed the sequence $T+L, T, L$ repeated.

\section{RESULTS}

Graphical representation of the results is shown in Figure 1, in which mean percent responding to the test stimuli during the CS period is illustrated in the lefthand panel and responding during the UCS period is shown in the right-hand panel.

\section{CS Period}

A split-plot ANOVA (Kirk, 1968) established that there were significant effects due to training level $[F(3,28)=14.13, p<.001]$, test stimulus $[F(2,56)=$ $87.87, \mathrm{p}<.001]$, and the Level by Test interaction $[F(6,56)=3.82, p<.005]$. A set of Scheffé multiple comparisons was performed in order to compare responding to the test stimuli at all levels of training. These comparisons demonstrated that there were no significant
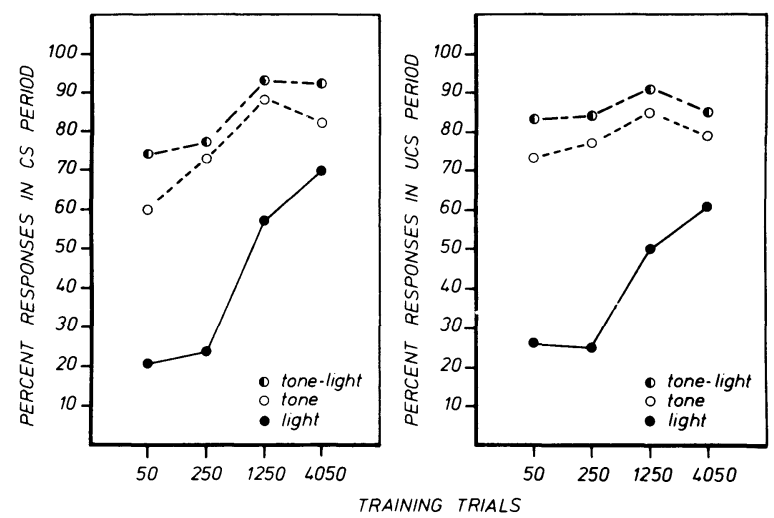

Figure 1. Mean percent responding to the $T+L$ compound or its components $(T, L)$ during extinction. Responses measured during the 5-sec CS period are shown in the left panel and those measured during the subsequent 3-sec UCS period are shown in the right panel. There were eight rats at each level of training.

differences in responding between $\mathrm{T}+\mathrm{L}$ and $\mathrm{T}$ at any training level $(\mathrm{ps}>.10)$. There were significant differences between $\mathrm{T}+\mathrm{L}$ and $\mathrm{L}$ for the 50-trial $(\mathrm{F}=67.02$, $p<.01)$, the 250-trial $(F=65.28, p<.01)$, and the 1,250 -trial groups $(\mathrm{F}=30.12, \mathrm{p}<.01)$. However, there was no difference in responding to $\mathrm{T}+\mathrm{L}$ and $\mathrm{L}$ for the 4,050 -trial group $\left[F=11.25, p>.10, F^{\prime}(10)=18.76\right]$, thus indicating that the interaction was attributable to an attenuation in the overshadowing of the light by the tone.

\section{UCS Period}

An identical analysis was performed on the data obtained during UCS periods. Again, the main effects due to training level $[\mathrm{F}(3,28)=6.34, \mathrm{p}<.005]$ and test stimulus $[\mathrm{F}(2,56)=80.03, \mathrm{p}<.001]$ were significant, as well as the Level by Stimulus interaction $[\mathrm{F}(6,56)=$ $2.82, \mathrm{p}<.025]$. Scheffé multiple comparisons yielded no differences between response levels to $\mathrm{T}+\mathrm{L}$ and $\mathrm{T}$ at any level of training ( $\mathrm{ps}>.10$ ). As for the CS period, there were again significant differences between responding to $\mathrm{T}+\mathrm{L}$ and $\mathrm{L}$ for the 50-, 250-, and 1,250-trial groups (ps<.05), but not for the 4,050-trial group $(F=9.46, p>.10)$. Therefore, whether responding was measured during the CS period or the UCS period, extended training with $\mathrm{T}+\mathrm{L}$ resulted in attenuating the overshadowing of the light.

\section{DISCUSSION}

The results show that, with extended compound training, overshadowing was attenuated such that the "overshadowed" stimulus (L) continuously gained strength while the "overshadowing" stimulus $(\mathrm{T})$ and the compound $(\mathrm{T}+\mathrm{L})$ maintained full strength. This finding is inconsistent with models assuming additivity and a fixed amount of available associative strength (e.g., Rescorla \& Wagner, 1972). After 4,050 trials, the mean response tendencies to $\mathrm{T}$ and $\mathrm{L}$ summed to over 1.5 times that of the $\mathrm{T}+\mathrm{L}$ compound. Statistically, there was no difference between $T+L$ and $T$ or $T+L$ and $L$, implying that the theoretical sum of response tendencies to the components was double that of the compound. 
In a sense, the present findings represent a case of spontaneous suprasummation (see Kremer, 1978). Suprasummation is said to be demonstrated when components, which were first trained separately, lose associative strength when subsequently trained as a compound. This result is attributed to the fact that when trained separately, each stimulus could acquire the total available reinforcement strength but when combined, they must divide that same total between them. Our results indicate that the initial separate training is not necessary for both components to gain full strength. Given this, it seems that continued compound training (as per Stage 2 in Kremer's procedure) might result in both components losing strength, that is, the development of a configure.

Recently, Durlach and Rescorla (1980) have proposed that within-compound associations, as well as CS-UCS associations, are formed. Our data, as they stand, are certainly consistent with such a notion. There are two difficulties, however. First, why was there loss of associative strength in Kremer's (1978) study? Presumably, the ability to develop within-compound associations implies a new source of reinforcement strength derivable from a CS's ability to sustain such an association when compounded. Both components would be assumed to have such strength after Stage 1 training, but something more akin to withincompound nonassociation occurred. Second, Gillette and Bellingham (1982) found that a nonreinforced saline-saccharin compound demonstrated a within-compound effect that dissipated with continued training and the final stage resulted in a configure being formed. That is, further training did not act to strengthen these "associations" but, rather, to weaken them. It is also for this reason we suspect that further training, in the present experiment, would result in eventual configuring.

The results of this study are also difficult to interpret with respect to Mackintosh's (1975) model of information value in stimulus selection. Since the light component was overshadowed for at least 250 trials, it would seem reasonable to assume that it was a redundant CS and should, therefore, have remained so. Notions involving concurrent interference (Revusky, 1971) also seem contraindicated, since they rest on the assumption that the formation of one CS-UCS association reduces the possibility of another such association.

A distribution of attention formulation (e.g., Sutherland \& Mackintosh, 1971) is more compatible with our findings. Such formulations assume, along with limited capacity to attend, that attention to one dimension momentarily limits attention to another simultaneously present dimension. They do not, however, assume that attention is fixed. Thus, it would be possible that over extended training trials, enough attention can be paid, within or between trials, to a relatively weak stimulus for it to acquire associability. Since a limit is not placed on available associative strength, a modestly attended cue could acquire strength, but at a proportionately reduced rate. Our apparatus would facilitate this outcome, since the compound stimulus emanated from within the magazine recess. Neither drinking from the dipper, during the UCS period, nor orienting toward and entering the magazine, during the CS period, would have disadvantaged either stimulus dimension. The difficulty for a distributed attention approach becomes more apparent in the case of equisalient stimuli. As mentioned, the eventual outcome is the loss of associative strength by the components as a function of the number of training trials. Although switching of attention can account for a component gaining strength and failure to switch can account for a component not gaining strength, neither can account for loss of associative strength.

It seems reasonably clear that Hull's (1943) stimulus interaction model will also not suffice as formulated. In addition to the criticisms outlined by James and Wagner (1980, pp. 204205 ), the model simply asserts that "afferent neural interaction" occurs (see also Mackintosh, 1974, pp. 49-50). The present data emphasize that what is needed is some explanation of how this interaction occurs in order to explain why an "overshadowed" component gains strength and equisalient stimuli lose strength, as a function of exposures.
The present results and those of previous configural conditioning studies suggest, at least, that stimulus processing is dynamic (Bellingham \& Gillette, in press; Gray \& Lethbridge, 1976; Thomas et al., 1968) and does not necessarily rely on reinforcement in order to produce changes in the perceived nature of stimuli (Gillette \& Bellingham, 1982).

Although it is not at all clear what approach would be most fruitful in order to account for such diverse phenomena as overshadowing and its attentuation, blocking, potentiation, and configuring, it is clear that a great deal more attention needs to be paid to changes in CS responsiveness as a function of the number of exposures.

The situation is neatly summarized by Logan's (1979) term the "mystery mechanism," that is, the mechanism that results in selective control, or lack of it, by elements of a stimulus complex in relation to their relative cue values. The implication is that a resolution of this problem lies at the very heart of an acceptable theory of learning and performance.

\section{REFERENCES}

Bellingham, W. P., \& Gillette, K. Spontaneous configuring to a tone-light compound using appetitive training. Learning and Motivation, in press.

Durlach, P. J., \& Rescorla, R. A. Potentiation rather than overshadowing in flavor-aversion learning: An analysis in terms of within compound associations. Journal of Experimental Psychology: Animal Behavior Processes, 1980, 6, 175-187.

Gillette, K., \& Bellingham, W. P. Loss of within-compound flavour associations: Configural preconditioning. Experimental Animal Behaviour, 1982, 1, 1-17.

Gray, T., \& Lethbridge, D. A. Configural conditioning in the CER: Loss of element strength after repeated reinforced compound CS trials. Learning and Motivation, 1976, 7, 532-539.

Hull, C. L. Principles of behavior. New York: Appleton-CenturyCrofts, 1943.

James, J. H., \& WAgneR, A. R. One-trial overshadowing: Evidence of distributive processing. Journal of Experimental Psychology: Animal Behavior Processes, 1980, 6, 188-205.

KIRK, R. E. Experimental design: Procedures for the behavioral sciences. Belmont, Calif: Wadsworth, 1968.

KREMER, E. F. The Rescorla-Wagner model: Losses in associative strength in compound conditioned stimuli. Journal of Experimental Psychology: Animal Behavior Processes, 1978, 4, 22-36.

Log An, F. A. Hybrid theory of operant conditioning. Psychological Review, 1979, 86, 507-541.

Mackintosh, N. J. An analysis of overshadowing and blocking. Quarterly Journal of Experimental Psychology, 1971, 23, 118-125.

MACKIntosh, N. J. The psychology of animal learning. London: Academic Press, 1974

Mackintosh, N. J. A theory of attention: Variations in the associability of stimuli with reinforcement. Psychological Review, 1975, 82, 276-298.

Rescorla, R. A., \& Wagner, A. R. A theory of Pavlovian conditioning: Variations in the effectiveness of reinforcement and nonreinforcement. In A. Black \& W. F. Prokasy (Eds.), Classical conditioning: II Current research and theory. New York: Appleton-Century-Crofts, 1972.

REvUSKY, $S$. The role of interference in association over a delay. In W. K. Honig, \& P. H. R. James (Eds.), Animal memory. New York: Academic Press, 1971.

Sutherland, N. S., \& Mackintosh, N. J. Mechanisms of animal discrimination learning. New York: Academic Press, 1971.

Thomas, D. R., Berman, D. L., Serednesky, G. E., \& Lyons, J. Information value and stimulus configuring as factors in conditioned reinforcement. Journal of Experimental Psychology, $1968,76,181-189$.

(Received for publication July 21, 1981.) 